\title{
Isolation of intestinal spirochaetes from homosexuals
}

\author{
DS TOMPKINS, MA WAUGH, ${ }^{*}$ E MARY COOKE \\ From the Department of Microbiology, School of Medicine, Leeds, and the *Department of Genito-Urinary \\ Medicine, General Infirmary, Leeds
}

SUMMARY Spirochaetes were isolated from rectal swabs of two homosexuals and the faeces of a third, using simple isolation techniques not previously applied to specimens of this type. The ease of culture of these organisms will enable their distribution and pathogenicity to be studied, particularly in relation to their significance in homosexuals.

The sexual transmission of enteric pathogens is recognised, and a high incidence of gastrointestinal parasites has been reported in communities of homosexuals. ${ }^{1}$ A non-treponemal spirochaete has been associated with a purulent rectal discharge in a homosexual. ${ }^{2}$

We report the isolation of spirochaetes using simple techniques from rectal swabs and faeces of three homosexuals. The culture medium, blood agar containing spectinomycin, was initially described for the isolation from pig faeces of Treponema hyodysenteriae, the aetiological agent of swine dysentery. ${ }^{3}$

\section{Isolation methods}

Rectal swabs were taken from passive homosexual males attending the Venereal Disease Clinic at the General Infirmary at Leeds. The swabs, transported in Stuart's medium, were inoculated on to $5 \%$ horse blood agar containing $400 \mathrm{mg} / \mathrm{l}$ spectinomycin. Anaerobic incubation in jars $\left(90 \% \mathrm{H}_{2}, 10 \% \mathrm{CO}_{2}\right)$ was continued at $37^{\circ} \mathrm{C}$ for 5 to 14 days. Growth of spirochaetes was detected as spreading, film-like, grey colonies producing complete haemolysis along the lines of spread of the inoculum.

Gram-staining, using dilute carbol fuchsin as a counterstain showed large, irregularly-coiled, Gramnegative spirochaetes (Fig. 1). Electron microscopy, with negative contrast, showed organisms of $0 \cdot 3-0.5$ $\mu \mathrm{m}$ diameter by $10-20 \mu \mathrm{m}$ with pointed ends, containing four or five axial fibrils (Fig. 2).

\section{Results}

Spirochaetes were isolated from three of 25 rectal swabs, after five days incubation. We failed to isolate

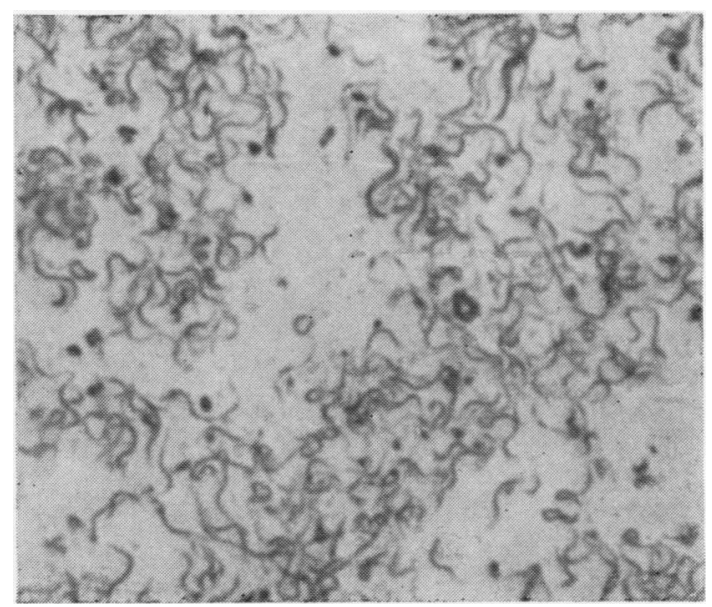

Fig. 1 Film stained by Becker's modification of Fontana's method. Original magnification $\times 2000$.

spirochaetes from 74 diarrhoeal faeces sent to the diagnostic laboratory but did culture the organism from one specimen of faeces from a homosexual. The four isolates of spirochaetes were from three patients, and their cases are presented below.

\section{CASE 1}

A 34-year-old homosexual, with a past history of anal herpes simplex virus and syphilis, attended the Venereal Disease Clinic for a "check-up" after a holiday in New York. Proctoscopy was normal and there were no gastrointestinal symptoms. Faecal examination for ova, cysts and parasites was negative, but spirochaetes were cultured from the specimen. A rectal swab taken at the same time was negative. Neisseria gonorrhoeae was not isolated and 


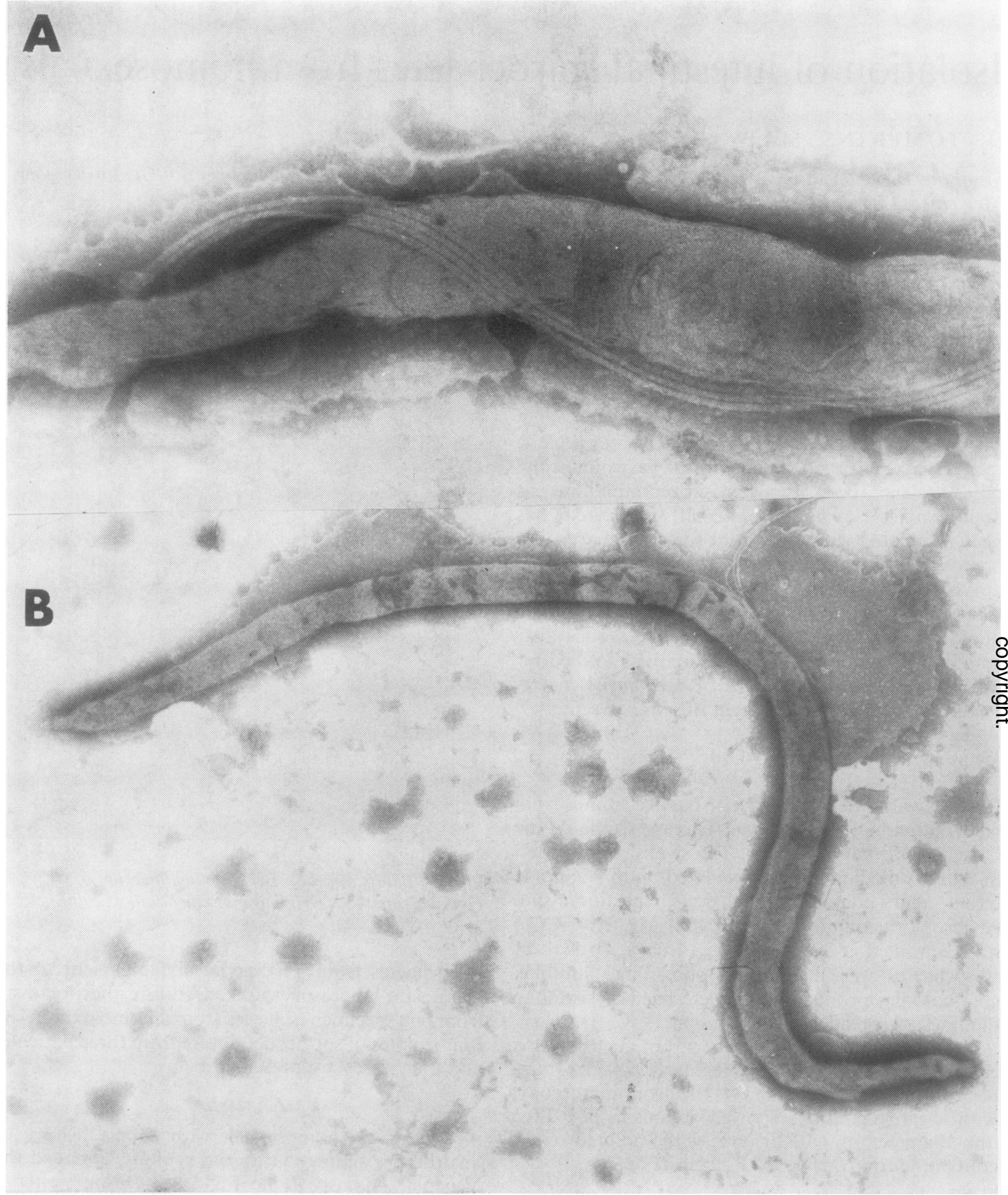

Fig. 2 Negatively stained electronmicrographs. In A, four axial fibrils are seen. Original magnification $A \times 74000$, $B \times 18500$.

syphilis serology indicated past infection. No chemotherapy was given and no spirochaetes were cultured from a rectal swab taken four months later.
CASE 2

A 38-year-old homosexual attended with urethral gonorrhoea. Cultures for $\mathrm{N}$ gonorrhoeae from rectum 
and pharynx, and syphilis serology were negative. Proctoscopy was normal and there were no gastrointestinal symptoms. Spirochaetes were grown from a rectal swab. The patient received $3.5 \mathrm{~g}$ ampicillin and $1 \mathrm{~g}$ probenecid, followed by a 14-day course of oxytetracycline $250 \mathrm{mg}$, four times daily, for postgonococcal urethritis. A rectal swab taken 14 days after the first was still positive for spirochaetes.

CASE 3

A 37-year-old homosexual with a past history of treated syphilis and gonorrhoea attended for a "check-up" after a holiday in Athens. Proctoscopy was normal and there were no gastrointestinal symptoms. Spirochaetes were cultured from a rectal swab. Cultures for $N$ gonorrhoeae were negative and syphilis serology indicated past infection. No chemotherapy was given and no further specimens obtained.

\section{Discussion}

It is difficult from the three cases described to assess the significance of colonisation by spirochaetes. Further studies are required on these easily cultured organisms. Previous descriptions of isolation techniques for intestinal spirochaetes have been complex, as strict anaerobiosis and special growth factors were thought to be necessary, ${ }^{4}$ but with the introduction of the technique described, it will be possible to assess the significance of these organisms in venereal disease and in bowel disorders.

Electron microscopy has been used to demonstrate spirochaetes in the intestines of healthy individuals ${ }^{5}$ and in patients with a variety of gastrointestinal disorders. ${ }^{6}$ An association between intestinal spirochaetosis and diarrhoea has been reported: ${ }^{7} 8$ however, we have so far failed to isolate spirochaetes from cases of diarrhoea.

The organism we isolated morphologically resembles Treponema vincentii, but the structure of spirochaetes is variable and may be altered by culture. ${ }^{9}$ Cultural characteristics resemble those of Treponema hyodysenteriae ${ }^{10}$ but the isolate from case 1 was non-identical with pathogenic and nonpathogenic porcine spirochaetes, by growth-in- hibition testing ( $\mathrm{Dr} \mathrm{R}$ Lemcke, personal communication, 1981).

Further studies are in progress to characterise these organisms more fully, to determine their pathogenicity and estimate their incidence in homosexuals and in heterosexuals.

We wish to thank Dr $\mathrm{K}$ Powell for the electronmicrographs, Mr D Hunter of the MAFF, Animal Health Centre, Leeds, and Dr JG Shoesmith, Department of Microbiology, University of Leeds, for their advice and encouragement, Dr R Lemcke and Mrs J Bew of the Institute of Research on Animal Diseases, Compton, Berks, who performed the growthinhibition tests.

\section{References}

${ }^{1}$ Felman YM, Ricciardi NB. Sexually transmitted enteric diseases. Bull NY Acad Med 1979;55:533-9.

${ }^{2}$ Kaplan LR, Takeuchi A. Purulent rectal discharge associated with a nontreponemal spirochete. $J A M A$ 1979;241:52-3.

${ }^{3}$ Songer JG, Kinyon JM, Harris DL. Selective medium for isolation of Treponema hyodysenteriae. J Clin Microbiol 1976;4:57-60.

${ }^{4}$ Holdeman LV, Cato EP, Moore WEC. Anaerobe laboratory manual 4th ed. Virginia Polytechnic Institute and State University, 1977.

${ }^{5}$ Takeuchi A, Jervis HR, Nakazawa H, Robinson DM. Spiral-shaped organisms on the surface colonic epithelium of the monkey and man. Am J Clin Nutr 1974;27: 1287-96.

${ }^{6}$ Lee FD, Kraszewski A, Gordon J, Howie JGR, McSeveney D, Harland WA. Intestinal spirochaetosis. Gut 1971 ;12: 126-33.

${ }^{7}$ Shera AG. Specific granular lesions associated with intestinal spirochaetosis. Br J Surg 1962;50:68-77.

${ }^{8} \mathrm{Gad} W$, Willen R, Furugard K, Fors B, Hradsky $M$. Intestinal spirochaetosis as a cause of longstanding diarrhoea. Ups J Med Sci 1977;82:49-54.

${ }^{9}$ Listgarten MA, Socransky SS. Electron microscopy as an aid in the taxonomic differentiation of oral spirochaetes. Arch Oral Biol 1965;10:127-38.

${ }^{10}$ Drasar BS, Hudson MJ. Spiral organisms in intestinal disease. In: Reeves DS, Geddes AM, eds. Recent advances in infection Vol 1. Edinburgh: Churchill Livingstone, 1979:41-53.

Requests for reprints to: Dr DS Tompkins, Department of Microbiology, School of Medicine, Leeds University, Leeds LS2 9NL, England. 